\title{
A CADAVERIC STUDY OF ANATOMICAL VARIATIONS OF THE NORMAL ARTERIAL PATTERN IN HELLENIC POPULATION
}

\author{
Eleni PANAGOULI ${ }^{1}$, Gregory TSOUCALAS ${ }^{2} \bowtie$, Theodoros G PAPAIOANNOU ${ }^{3}$, \\ Vasilios THOMAIDIS ${ }^{2}$, Aliki FISKA ${ }^{2}$, Dionysios VENIERATOS ${ }^{1}$, Panagiotis SKANDALAKIS $^{1}$
}

${ }^{1}$ Department of Anatomy, Medical School, National and Kapodistrian University of Athens, Greece

${ }^{2}$ Department of Anatomy, School of Medicine, Democritus University of Thrace, Alexandroupolis, Greece ${ }^{3}$ First Dept. of Cardiology, Hippokration Hospital, Medical School, National and Kapodistrian University of Athens, Athens, Greece

Received 14 Oct 2018, Accepted 27 Nov 2018

https://doi.org/10.31688/ABMU.2018.53.4.01

\section{Abstract}

Introduction. Arterial variations may cause significant complications during diagnostic and interventional procedures.

The objective of the study. Our study examined 73 donated cadavers in the National and Kapodistrian University of Athens, in an effort to unearth possible artery alternations.

Material and methods. The major branches of the abdominal aorta, the arteries of the limps and the neck were inquired.

Results. In $58.9 \%$ of the cadavers no arterial variation was found, whereas one, two and three alternations at the same cadaver were observed in $21.9 \%$, $12.3 \%$ and $6.8 \%$ respectively. The most common anatomical variations were noted in the vascular branching of the celiac trunk found in $24.7 \%$ of the cadavers. Conclusions. There was no statistically significant difference between the two genders concerning the frequency of the observed arterial variations $(p<0.05)$.

\section{Résumé}

Etude cadavérique des variations anatomiques d'un modèle artériel normal de la population Hellénique

Introduction. Les variations artérielles peuvent entraîner des complications importantes lors de procédures de diagnostic et d'intervention.

L'objectif de l'étude. Notre étude a examiné $73 \mathrm{ca}$ davres qui ont été donnés à l'Université Nationale et Kapodistrienne d'Athènes, dans le but de découvrir de possibles alternations des artères.

Matériel et méthodes. Les principales branches de l'aorte abdominale, les artères de la boîte et du cou ont été examinées.

Résultats. Aucune variation artérielle n'a été constatée chez 58,9\% des cadavres, alors qu'une, deux et trois alternances chez le même cadavre ont été observées à $21,9 \%, 12,3 \%$ et $6,8 \%$ respectivement. Les variations anatomiques les plus courantes ont été observées dans la ramification vasculaire du tronc cœeliaque retrouvée chez $24,7 \%$ des cadavres. 
Keywords: artery variations, cadaveric study, celiac artery, superior mesenteric artery, inferior mesenteric artery, renal artery.
Conclusions. Il n'y avait pas de différence statistiquement significative entre les deux sexes concernant la fréquence des variations artérielles observées $(\mathrm{p}<0,05)$.

Mots-clés: variations artérielles, étude cadavérique, artère coeliaque, artère mésentérique supérieure, artère mésentérique inférieure, artère rénale.

\section{INTRODUCTION}

The beauty and diversity of the human arterial tree attract the research and clinical interest of vascular and general surgeons, cardiologists, interventional radiologists and other medical and non-medical scientists. To learn its complexity presents a crux of its own. A better knowledge of anatomical variations of the normal human arterial pattern may improve surgical application and decrease complications. In reality, morphology and anatomical variations of the arteries are depicted in such a prevalence among humans that a comprehensive and illustrative awareness of arterial variations beyond of normal anatomy is crucial ${ }^{1}$.

Variations in the conduit arteries supplying organs and tissues with blood are usually harmless. Nevertheless, to correctly detect, understand and interpret both normal arterial trajectories and their possible changes is of great importance before any external intervention. On the other hand, some anatomical variations could present a negative effect concerning blood supply. Vascular structure is the result of a complex biological process, genetically programmed and controlled, while various triggers during embryological evolution may result in anomalies which are usually considered as abnormalities. In large vessels, mainly, variations are due to the persistence of embryonic dispositions ${ }^{2}$. As the true frequency of altered patterns depends basically on the ability of the investigator-anatomist to recognize them, dissections require specialized personnel and in-depth comprehension of the possible alternations of the human cannulation ${ }^{3}$.

THE OBJECTIVE OF OUR STUDY was to investigate in a cadaveric series and present the possible variations in the main vessels of the human body and their clinical significance.

\section{Material AND MEthods}

A summary of 73 embalmed human cadavers of Caucasian (Hellenic) origin (38 male and 35 female) was examined during routine educational dissection in cadavers donated at the Anatomy Department of the Medical School of the National and Kapodistrian
University of Athens. The cadavers derived from body donation with informed consent written and signed (with signature authentication) by the donor himself. The protocol for the present research had been approved by the ethics committee of our institution.

The following arteries were studied, in order to investigate the existence of anatomical variations: a) Major branches of the abdominal aorta: the celiac artery (CA), the superior and inferior mesenteric arteries (SMA \& IMA), the renal arteries (RA), b) Arteries of the limps: the profundi femoris arteries (PFA) and the profundi brachii arteries (PBA) bilaterally, and c) Arteries of the neck: brachiocephalic artery (BCA), and the vertebral arteries (VA) bilaterally.

Categorical variables are presented as absolute frequencies and percentages (\%). Fischer's exact test and cross-tabulations were used to compare the frequencies of arterial variations between male and female cadavers. Statistical significance level was accepted for $\mathrm{p}$-values less than 0.05 . Statistical analysis was carried out using IBM SPSS Statistics for

\section{Results}

The absolute frequency and the percentage of subjects with one, two, three or four anatomical variation(s) or without any variation are reported in Table 1. It was observed that $58.9 \%$ of the cadavers did not present any arterial variation, whereas one, two and three variations at the same cadaver were observed at $21.9 \%, 12.3 \%$ and $6.8 \%$ of the examined sample respectively.

The absolute frequency and percentage of each different type of the observed arterial variations are reported in Table 2. The most common anatomical variations that were determined in our cadaveric investigation were the vascular branching alternations of the CT found in $24.7 \%$ of the cadavers, the additional RA discovered in 20.5\% (right RA $11 \%$, left RA 9.6\%) and variations of the left vertebral artery in $8.2 \%$. Among these variations a complete absence of a vessel was observed. Thus, in two cadavers the CT (2.7\%) was absent, in one the left PFA (1.4\%) and in another one the BCA (1.4\%). No variations were found in the SMA, right VA and right PFA. Windows version 25.0. 
The absolute frequency and percentage of different combinations of arterial variations observed at the examined cadavers is reported in Table 3. Combination of variations of the celiac artery and unilateral ARA was the most frequent one (5.5\%) with the next most frequent being the variation of the celiac artery combined with unilateral common trunk of the profunda brachii artery (2.75\%). Finally, Table 4 provides the variations observed at each cadaver. The absolute frequency of variations observed at male and female cadavers are reported in Table 5 . There was no statistically significant difference between the two genders concerning the frequency of the observed arterial variations $(\mathrm{p}<0.05)$.

\section{Discussion}

Our team of anatomists firstly examined all major branches of the abdominal aorta. The celiac artery, or as more commonly referred the celiac trunk

Table 1. Anatomical variations in cadavers arteries

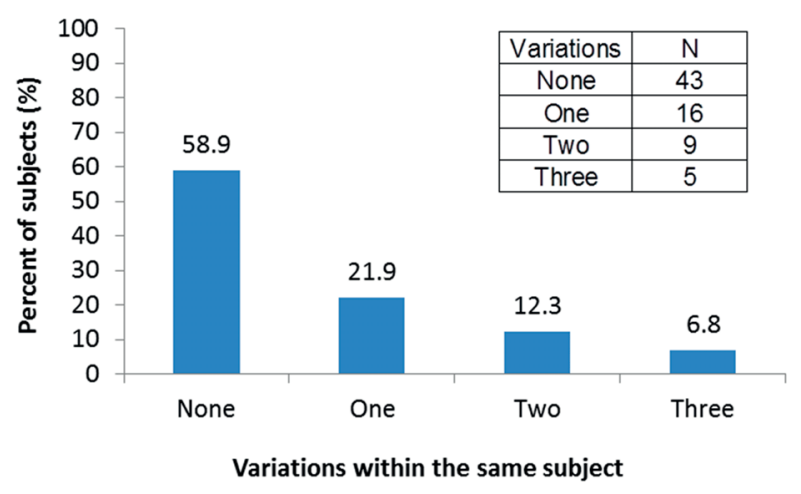

Table 2. Absolute frequency and percentage of different types of anatomical variations

\begin{tabular}{clcc}
\hline No. & Variation & Number & Percent (\%) \\
\hline 1 & celiac artery & 18 & 24.7 \\
\hline 2 & right renal artery & 8 & 11.0 \\
\hline 3 & left renal artery & 7 & 9.6 \\
\hline 4 & left vertebral artery & 6 & 8.2 \\
\hline 5 & left profunda femoral artery & 4 & 5.5 \\
\hline 6 & $\begin{array}{l}\text { right profunda brachii } \\
\text { artery }\end{array}$ & 3 & 4.1 \\
\hline 7 & left profunda brachii artery & 2 & 2.7 \\
\hline 8 & brachiocephalic artery & 2 & 2.7 \\
\hline 9 & inferior mesenteric artery & 1 & 1.4 \\
\hline 10 & superior mesenteric artery & 0 & 0.0 \\
\hline 11 & $\begin{array}{l}\text { right profunda femoral } \\
\text { artery }\end{array}$ & 0 & 0.0 \\
\hline 12 & right vertebral artery & 0 & 0.0 \\
\hline
\end{tabular}

(CT), constitutes a surgically significant splanchnic branch, the first of the abdominal aorta. CT is a short arterial segment which arises just below the aortic hiatus at the level of the T12/L1 vertebral bodies and trifurcates after a short course to the common hepatic, splenic, and left gastric arteries forming a tripod, known as "tripus Halleri" ${ }^{44-6}$. This tripod may be a true one with a common origin of all the three arteries, or a false one, where one of its branches - most commonly the left gastric artery-arises earlier (separate) along the celiac trunk. A series of classification attempts exist in the literature. Despite all anomalies reported on the normal pattern of the CT, several anatomical variations were also discussed. Thus, a series of cases noted the absence of one of its branches (bifurcation or incomplete CT), additional branches, common origin with the superior mesenteric artery (celiac-mesenteric trunk), common origin with the superior and inferior mesenteric artery (celiac-bimesenteric trunk) and total absence of the CT (Figure 1 ${ }^{7-10}$.

Table 3. Combinations of anatomical variations in cadaver's arteries

\begin{tabular}{|c|c|c|c|}
\hline No & $\begin{array}{l}\text { Combinations of anatomical } \\
\text { variations }\end{array}$ & Percentage & No in total \\
\hline 1 & $\begin{array}{l}\text { Variation of the celiac artery } \\
\text { and unilateral additional renal } \\
\text { artery }\end{array}$ & $5.5 \%$ & $4 / 73$ \\
\hline 2 & $\begin{array}{l}\text { Two variations of the celiac } \\
\text { artery }\end{array}$ & $1.4 \%$ & $1 / 73$ \\
\hline 3 & $\begin{array}{l}\text { Bilateral additional renal } \\
\text { artery }\end{array}$ & $1.4 \%$ & $1 / 73$ \\
\hline 4 & $\begin{array}{l}\text { Variation of the celiac artery } \\
\text { and unilateral common trunk } \\
\text { of the profunda brachii artery }\end{array}$ & $2.75 \%$ & $2 / 73$ \\
\hline 5 & $\begin{array}{l}\text { Variation of the celiac and } \\
\text { brachiocephalic artery }\end{array}$ & $1.4 \%$ & $1 / 73$ \\
\hline 6 & $\begin{array}{l}\text { Common trunk of the pro- } \\
\text { funda brachii artery bilateral }\end{array}$ & $1.4 \%$ & $1 / 73$ \\
\hline 7 & $\begin{array}{l}\text { Variation of the celiac artery } \\
\text { and absence of the profunda } \\
\text { femoris artery }\end{array}$ & $1.4 \%$ & $1 / 73$ \\
\hline 8 & $\begin{array}{l}\text { Variation of the celiac and } \\
\text { inferior mesenteric artery and } \\
\text { unilateral additional renal } \\
\text { artery }\end{array}$ & $1.4 \%$ & $1 / 73$ \\
\hline 9 & $\begin{array}{l}\text { Variation of the celiac artery, } \\
\text { common trunk of the profun- } \\
\text { da brachii artery and unilat- } \\
\text { eral additional renal artery }\end{array}$ & $1.4 \%$ & $1 / 73$ \\
\hline 10 & $\begin{array}{l}\text { Variation of the celiac artery } \\
\text { and bilateral additional renal } \\
\text { artery }\end{array}$ & $1.4 \%$ & $1 / 73$ \\
\hline 11 & $\begin{array}{l}\text { Two variations of the celiac } \\
\text { artery and variation of the left } \\
\text { vertebral artery and unilateral } \\
\text { additional renal artery }\end{array}$ & $1.4 \%$ & $1 / 73$ \\
\hline
\end{tabular}


Table 4. Anatomical variation(s) per cadaver

\begin{tabular}{|c|c|c|}
\hline No & Sex & Variation(s) \\
\hline 1 & $\mathrm{~F}$ & Absence of the celiac trunk \\
\hline 2 & M & $\begin{array}{l}\text { Incomplete (false) celiac trunk, Additional left } \\
\text { renal artery }\end{array}$ \\
\hline 3 & M & $\begin{array}{l}\text { Incomplete (false) celiac trunk, Common } \\
\text { trunk of the right profunda brachii artery }\end{array}$ \\
\hline 4 & $\mathrm{~F}$ & $\begin{array}{l}\text { Incomplete (false) celiac trunk, Additional } \\
\text { right renal artery }\end{array}$ \\
\hline 5 & M & Incomplete (false) celiac trunk \\
\hline 6 & $\mathrm{~F}$ & $\begin{array}{l}\text { Incomplete (false) celiac trunk, Additional left } \\
\text { renal artery }\end{array}$ \\
\hline 7 & M & Incomplete (false) celiac trunk \\
\hline 8 & M & $\begin{array}{l}\text { Incomplete (false) celiac trunk, Additional left } \\
\text { renal artery, Additional right renal artery }\end{array}$ \\
\hline 9 & M & $\begin{array}{l}\text { Additional left renal artery, Additional right } \\
\text { renal artery }\end{array}$ \\
\hline 10 & M & Additional right renal artery \\
\hline 11 & $\mathrm{~F}$ & Additional right renal artery \\
\hline 12 & $\mathrm{~F}$ & Additional right renal artery \\
\hline 13 & M & Additional right renal artery \\
\hline 14 & M & Absence of the profounda femoris artery \\
\hline 15 & $\mathrm{~F}$ & $\begin{array}{l}\text { Origin of the left vertebral artery from the } \\
\text { aortic arch }\end{array}$ \\
\hline 16 & $\mathrm{~F}$ & $\begin{array}{l}\text { Origin of the left vertebral artery from the } \\
\text { aortic arch }\end{array}$ \\
\hline 17 & $\mathrm{~F}$ & $\begin{array}{l}\text { Origin of the left vertebral artery from the } \\
\text { aortic arch }\end{array}$ \\
\hline 18 & M & $\begin{array}{l}\text { Origin of the left vertebral artery from the } \\
\text { aortic arch }\end{array}$ \\
\hline 19 & $\mathrm{M}$ & Double vertebral artery \\
\hline 20 & M & Absence of the brachiocephalic artery \\
\hline 21 & $\mathrm{~F}$ & $\begin{array}{l}\text { Additional right renal artery, Anomalous } \\
\text { origin of right inferior phrenic artery from the } \\
\text { celiac artery, Origin of the left vertebral artery } \\
\text { from the aortic arch }\end{array}$ \\
\hline 22 & $\mathrm{~F}$ & $\begin{array}{l}\text { Incomplete (false) celiac trunk, Additional } \\
\text { left renal artery, Common trunk of the left } \\
\text { profunda brachii artery }\end{array}$ \\
\hline 23 & $\mathrm{~F}$ & $\begin{array}{l}\text { Common trunk of the right profunda brachii } \\
\text { artery, Common trunk of the left profunda } \\
\text { brachii artery }\end{array}$ \\
\hline 24 & M & Incomplete (false) celiac trunk \\
\hline 25 & M & $\begin{array}{l}\text { Incomplete (false) celiac trunk, Anomalous } \\
\text { origin of the lumbar artery from the celiac } \\
\text { artery }\end{array}$ \\
\hline 26 & $\mathrm{~F}$ & $\begin{array}{l}\text { Absence of the celiac trunk, Additional left } \\
\text { renal artery (Origin of the additional renal } \\
\text { artery from the left common iliac artery) }\end{array}$ \\
\hline 27 & M & $\begin{array}{l}\text { Incomplete (false) celiac trunk, Common } \\
\text { trunk of the right profunda brachii artery }\end{array}$ \\
\hline 28 & M & $\begin{array}{l}\text { Incomplete (false) celiac trunk, Additional left } \\
\text { renal artery, Origin of the inferior mesenteric } \\
\text { artery from the left common iliac artery }\end{array}$ \\
\hline 29 & $\mathrm{~F}$ & $\begin{array}{l}\text { Incomplete (false) celiac trunk, Large brachio- } \\
\text { cephalic artery }\end{array}$ \\
\hline 30 & $\mathrm{~F}$ & Double profounda femoris artery \\
\hline
\end{tabular}

Table 5. Absolute frequency of variations observed at each gender. Percentages of males and females within each variation group are reported

\begin{tabular}{lcccc}
\hline & \multicolumn{2}{c}{ MALES } & \multicolumn{2}{c}{ FEMALES } \\
\hline \multicolumn{1}{c}{ Variation } & $N$ & $\%$ & $N$ & $\%$ \\
\hline celiac artery & 11 & 61.1 & 7 & 39.9 \\
\hline right renal artery & 4 & 50.0 & 4 & 50.0 \\
\hline $\begin{array}{l}\text { left renal artery } \\
\text { left vertebral artery }\end{array}$ & 4 & 57.1 & 3 & 42.9 \\
\hline $\begin{array}{l}\text { right profunda brachii } \\
\text { artery }\end{array}$ & 2 & 66.7 & 1 & 33.3 \\
$\begin{array}{l}\text { left profunda brachii } \\
\text { artery }\end{array}$ & 0 & 0.0 & 2 & 100.0 \\
\hline $\begin{array}{l}\text { left profunda femoral } \\
\text { artery }\end{array}$ & 1 & 25.0 & 3 & 75.0 \\
\hline $\begin{array}{l}\text { inferior mesenteric artery } \\
\text { brachiocephalic artery }\end{array}$ & 1 & 100.0 & 0 & 0.0 \\
\hline $\begin{array}{l}\text { superior mesenteric artery } \\
\text { right profunda femoral }\end{array}$ & 0 & - & 0 & - \\
\hline $\begin{array}{l}\text { artery } \\
\text { right vertebral artery }\end{array}$ & 0 & - & 0 & - \\
\hline
\end{tabular}

CT variation is found in approximately $10 \%$ of the general population, while an incomplete CT was reported in about $9.5 \%$ of the studied individuals ${ }^{11}$, with a complete absence of the trunk noted as a rare finding ${ }^{5,11-12}$. Our study demonstrated increased numbers concerning $2.7 \%$ for $\mathrm{CT}$ absence. On the other hand, we have encountered decreased percentage concerning the anomalous origin of the inferior phrenic artery from the celiac artery which is reported in literature in high percentages from 32.2 up to $42.2 \%{ }^{13}$, while we report only a $1.4 \%$. Anomalous origin of the lumbar artery from the celiac artery reported as an uncommon variation ${ }^{5}$, confirmed by our study which notes $1.4 \%$ for this branching alternation. The rest of the variations concerned the existence of a false tripod. Knowledge of the CT anatomy and its branching pattern, normal and varied, is of great importance due to number of current medical procedures in the area, such as vascular operations (treatment of abdominal aortic aneurysms), abdominal and visceral surgery (hepatic, pancreatic, and esophagogastric operations) and organ transplantations ${ }^{4.5}$.

The superior mesenteric artery (SMA) originates from the abdominal aorta approximately $1 \mathrm{~cm}$ below the CT at the level of the L1/2 intervertrebral disc. Although the variations in this artery are very common and numerous we have detected no anatomical variations in none of our dissected cadavers. The inferior mesenteric artery (IMA) arises from the front of the abdominal aorta (its third main branch) behind the third-horizontal part of the duodenum at the level 


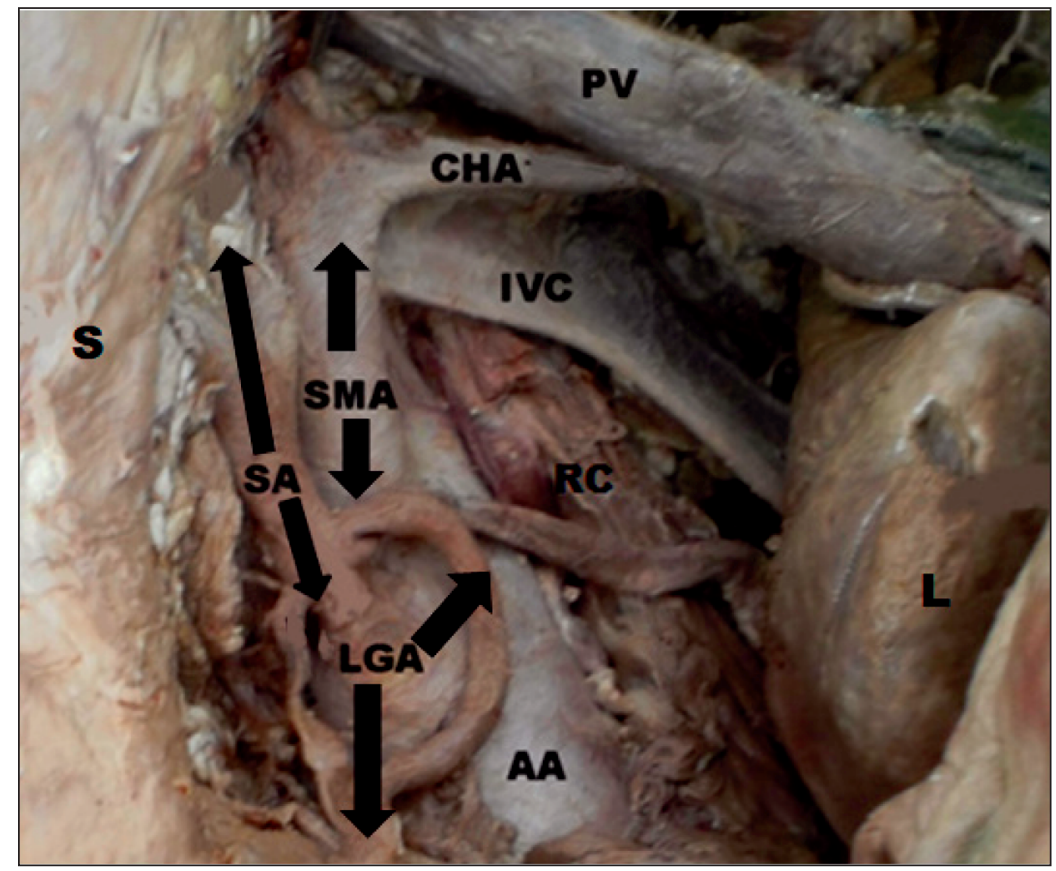

Figure 1. Absence of celiac trunk (cadaver no 1). AA: abdominal aorta, SA: splenic artery, CHA: common hepatic artery, LGA: left gastric artery, SMA: superior mesenteric artery, IVC: inferior vena cava, PV: portal vein, S: stomach, L: liver, RC: right crus of the diaphragm, CT: celiac trunk.

of $\mathrm{L} 3$ vertebra, about $3-4 \mathrm{~cm}$ above the termination (bifurcation) of the abdominal aorta. It descends anteriorly to the aorta and then passes to the left as it continues inferiorly. Its branching includes the left colic artery, several sigmoid arteries and the superior rectal artery. Although IMA's divisional branches showed important variability in terms of distance to the origin and repartition, its anatomical variations are rare ${ }^{14-15}$. We report only one variation of the IMA, concerning its origin from the left common iliac artery $(1.4 \%)$. For the diagnosis of intestinal angina and ischemic colitis is essential for the radiologist to understand all possible variant of the IMA. The same apply for a surgeon in the case of intestinal operations (malignancies, compressions, occlusive disease, IMA reimplantation $)^{16}$.

The renal arteries (RA), right and left, arise from the anterolateral aspect of abdominal aorta, at approximately the level of the superior margin of L1-L2, immediately caudal to the origin of the superior mesenteric artery. Two types of anatomical variations are reported. The first is referred as early division and characterized by branching of the main renal arteries into segmental branches proximal to the hilum. The second is known as the extra renal arterial branches, which can further divide into accessory (hilar) and aberrant (polar) arteries ${ }^{17-18}$.

Apart from the direct variations of the RA, a common and clinically important anatomical variation is the additional RA, encountered in around
$30 \%$ of the human individuals (24\% unilateral, $5-10 \%$ bilateral $)^{17,19}$. Some studies report higher incidence up to $75.7 \%{ }^{20}$. Several terms have been used for multiple renal arteries such as ,accessory“, „supernumerary“, „supplementary“, „extra“, „aberrant“, „ectopic“, „plural“ and „additional“14. Our study agrees with those findings, reporting an additional RA in $20.5 \%$ of the dissected cadavers. The gradual increase in renal interventions, renal surgery, renal transplantation and therapeutic embolization, or intravascular stent placement, makes the recognition of the RA variations crucial for the successful accomplishment of various procedures ${ }^{17}$.

We have secondly investigated the arteries of the limps, both upper and lower. The profunda brachii (PBA) artery was examined bilaterally. PBA is the largest branch of the brachial artery, which arises from the medial and posterior parts of the brachial artery just below the border of the teres major and then passes into and supplies the posterior compartment of the arm. After its entrance it passes along the radial groove on the posterior surface of the humerus deep to the lateral head of the triceps brachii muscle. Its final branches supply adjacent muscles and anastomose with the posterior circumflex humeral artery ${ }^{21}$. Most reported anatomic variations of the PBA are related to duplication of the vascular pedicle within the septum ${ }^{22}$.

The incidence of double PBA has been reported to be $4 \%$ to $12 \%$ on various studies ${ }^{22}$, origin 


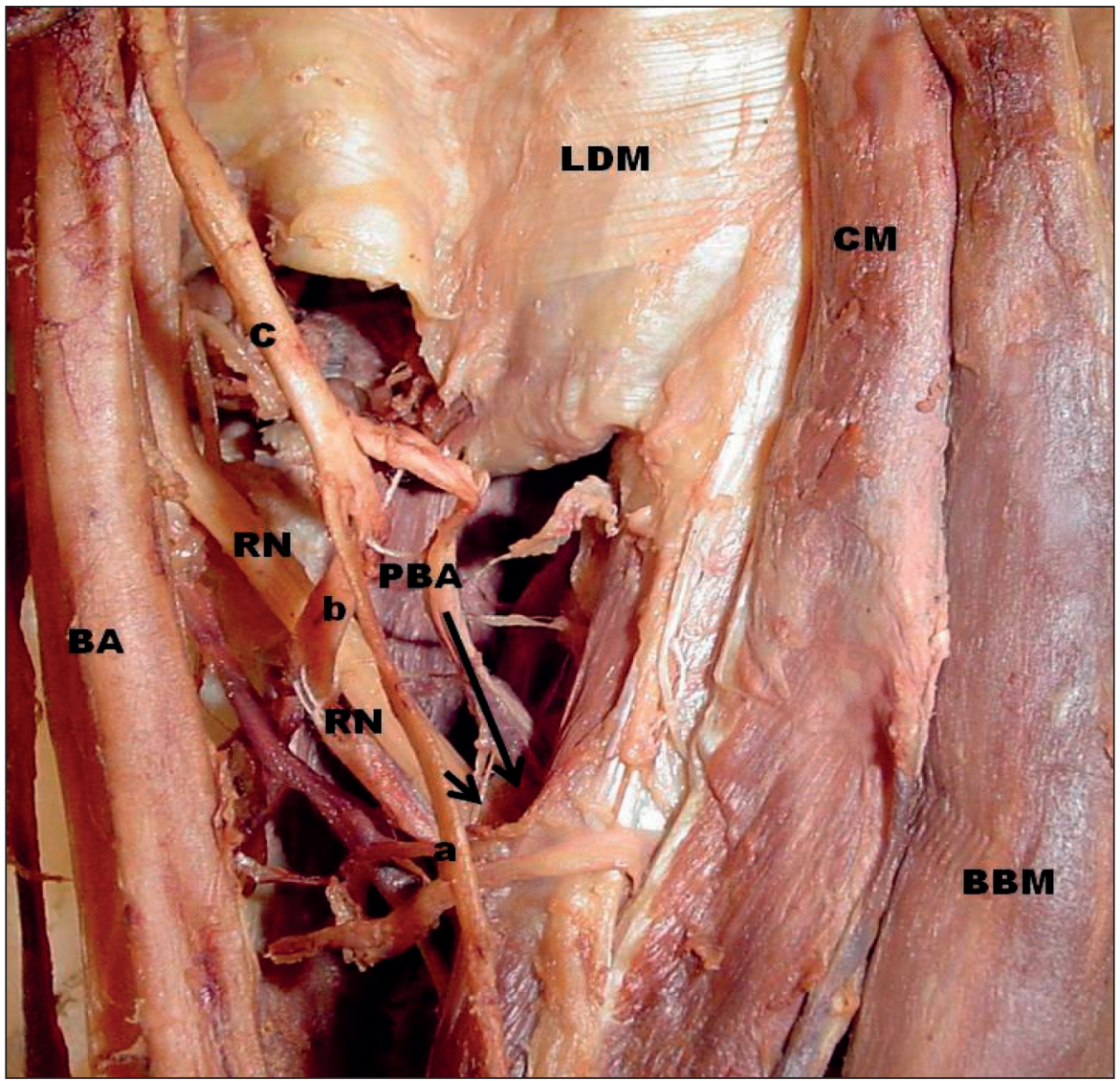

Figure 2. Common trunk of the (left) profunda brachii artery (cadaver no 23). BA: brachial artery, PBA: profunda brachii artery, RN: radial nerve, BBM: the biceps brachii muscle, CM: coracobrachialis muscle, LDM: latissimus dorsal muscle, a: muscular branch for the biceps brachii muscle, b: muscular branch for the coracobrachialis muscle, C: common trunk.

of PBA from posterior circumflex humeral (7\%), origin of posterior circumflex humeral artery from PBA $(16 \%)^{23}$. Agenesis of the brachial artery, profunda brachii artery has been noted ${ }^{24}$, while occasionally the subscapular, circumflex humeral, and profunda brachii arteries arise from a common trunk from the axillary artery (Figure 2) ${ }^{25-27}$. We report an incidence of $6.8 \%$ of a PBA having a common trunk in its origin. To recognize potential variations of the PBA is needed for possible revascularization of the flaps used for head and neck reconstruction ${ }^{22}$, and is useful during an ultrasound examination ${ }^{28}$.

The profunda femoris artery (PFA) is the largest branch of femoral artery and the main source of blood supply to the muscles in the area of the thigh. It is given off from the lateral side of the femoral artery in the femoral triangle and passes downward and medially to the apex of the femoral triangle. Next it descends into the abductor longus ${ }^{29}$. As far as the anatomical variations of the PFA concerns, it takes off in a dorsolateral direction in about $50 \%$ of cases and it is located strictly dorsal in about $40 \%$, a medial origin is encountered in $10 \%$ of cases, while its duplication in a medial and a lateral course is extremely rare
(Figure 3$)^{30}$. However, our findings note a $2.7 \%$ of its duplication. Moreover, PFA may be rarely absent ${ }^{31}$, may present a trifurcation in $4.5 \%$ of cases and occasionally the superficial branches of femoral artery took origin from PFA instead of the femoral artery as it should ${ }^{32}$. Our study is in agreement with the international literature, reporting only a $1.4 \%$ for complete absence and no other branchial modifications. To recognize PFA variations is helpful for a series of clinical procedures like arteriography, ultrasonography and Doppler imaging and haemodialysis ${ }^{32}$, as most of the anatomical variations in the arterial pattern of the lower limb arteries cause no symptoms ${ }^{30}$.

Finally, we went over to the arteries of the neck. The brachiocephalic artery (BCA) is the first or anterior branch of the aortic arch. It arises behind the manubrium and ascends as far as the right sternoclavicular joint, there to be divided into two terminal branches, the right subclavian and right common carotid arteries ${ }^{33}$.

Anatomic variations of the BCA include tortuous brachiocephalic artery, a left brachiocephalic artery which bifurcates to form the left subclavian and common carotid arteries in $27 \%$ of the cases 


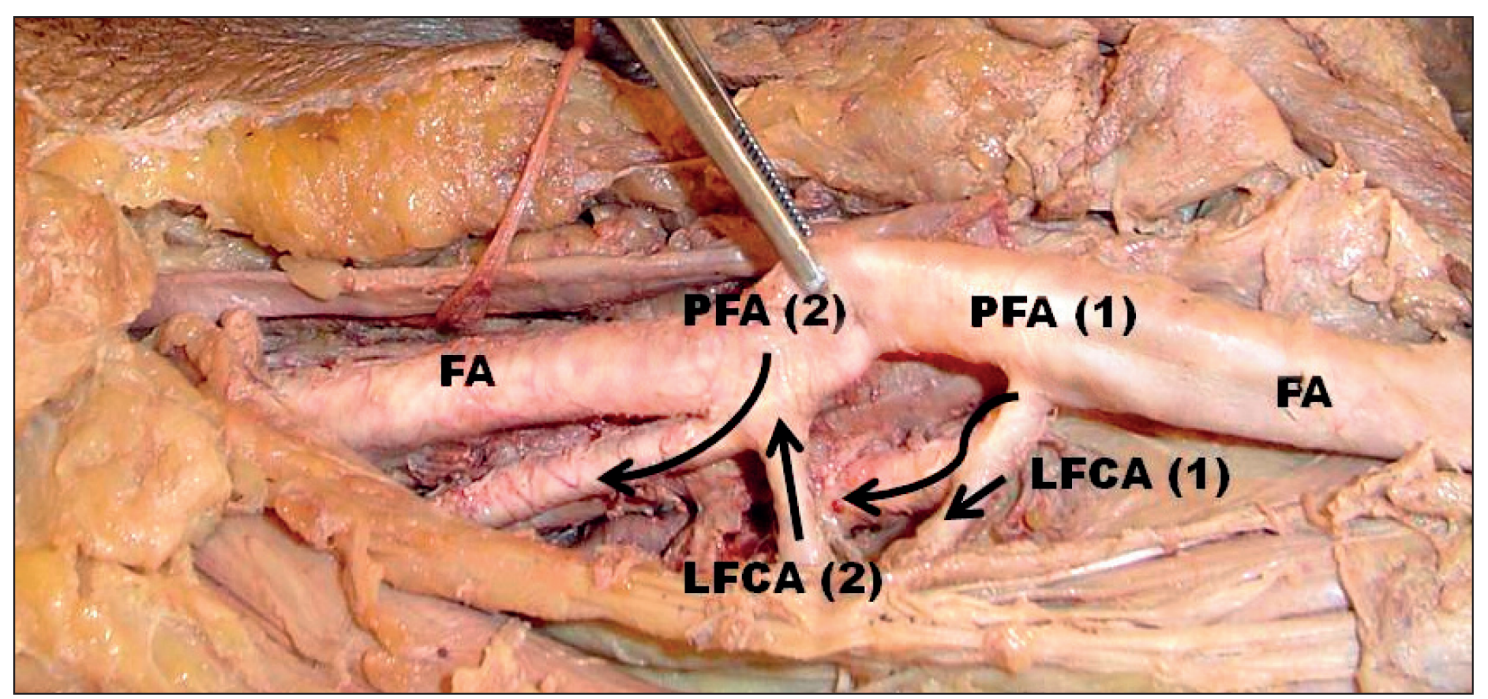

Figure 3. Double (left) profounda femoris artery (cadaver no 30). FA: femoral artery, PFA: profunda femoris artery $(1+2)$, LFCA: lateral femoral circumflex artery $(1+2)$.

and absence of the BCA in 2.5\% of the cases ${ }^{34}$. BCA may appear disproportionately large (steroids use, temporal arteritis, congenital) ${ }^{35}$, as in one case of our study (1.4\%), in which we encountered a large $\mathrm{BCA}$ with a length of approximately $5.8 \mathrm{~cm}$. We also note a complete absence of the BCA in a $1.4 \%$ of our dissected cadavers. Comprehension of basic angiographic anatomy of the aortic arch and the BCA is an essential component for the successful carotid artery access and the safe execution of the carotid artery stenting procedure ${ }^{36-37}$, as well as for a successful open tracheostomy ${ }^{38}$.

The vertebral artery (VA) is one of the principal arteries which supplies the brain. It is the first and largest branch of the first part of the subclavian artery, beginning in the root of the neck as a branch which arises from the super-posterior aspect of the first part of the subclavian artery. Usually, its anatomic course is divided into four segments ${ }^{39}$.

In approximately $5 \%$ of the cases the VA arises directly from the aortic arch (left VA 3.6\%-5\%, right VA rare approximately $0.14 \%$ ), between the origin of the left common carotid and left subclavian arteries. We have encountered 6 such cases, reporting $8.2 \%$ of an origin of the left VA directly from the aortic arch, while none such case concerning the right VA was discovered. Other anatomic areas of origin are also reported in the literature ${ }^{40}$, but not met in our dissected cadavers. Rarely is reported the duplication of a VA, in agreement with our study which reports only a $1.4 \%$. Moreover, a large VA is reported, presenting a pathological entity (large artery disease), the second most common mechanism accounting from approximately for the $32 \%$ of the cases with ischemia of the posterior cerebral circulation. This is due to the hemodynamic bases or by occlusion of important penetrating of circumferential branches arising from the diseased vessel ${ }^{39}$. To minimize the risk of VA injury in several procedures, detailed knowledge of VA variants is crucial for both endovascular intervention and diagnostic radiology in the treatment process of patients with cerebrovascular disease ${ }^{40}$.

As a plethora of embryological malformations may occur, combined complex of vascular branching anomalies may involve different vascular districts, resulting to a combination of two or more concurrent arterial variations $s^{2,24,31,41-43}$. Our study reports a $12.3 \%$ for branching alternation in two different vascular districts and a $6.8 \%$ for three. Interventional practitioners should have in mind that more than one vascular variations may exist locally or at distance within the human body.

\section{Conclusion}

Ignorance about arterial anatomy may have important clinical implications as well as cause a fatal misguidance in pre-procedural planning either for surgery or endovascular approach. In-depth knowledge of topographic surgical anatomy concerning deviations, variations, malformations of the circulatory system is paramount, serving as the most helpful information for radiologists, plastic surgeons and vascular surgeons ${ }^{44}$. Hence, this study may help the clinicians to avoid iatrogenic complications, as to prevent diagnostic errors, influence surgical tactics and interventional procedures and avoid complications during surgery. 


\section{Compliance with Ethics Requirements:}

„The authors declare no conflict of interest regarding this article"

"The authors declare that all the procedures and experiments of this study respect the ethical standards in the Helsinki Declaration of 1975, as revised in 2008(5), as well as the national law. Informed consent was obtained from all the patients included in the study"

"No funding for this study"

\section{References}

1. Wacker FK, Lippert H, Pabst R. Arterial Variations in Humans: Key Reference for Radiologists and Surgeons. Thieme, Stuttgart, 2017.

2. Lausjaunias P, Berenstein A, ter Brugge KG. Clinical Vascular Anatomy and Variations. Springer Verlag, Berlin, 2013.

3. Berenstein A, Lausjaunias P. Surgical Neuroangiography. Springer Verlag, Berlin, 2012.

4. Panagouli E, Venieratos D, Lolis E, Skandalakis P. Variations in the anatomy of the celiac trunk: A systematic review and clinical implications. Annals of Anatomy 2013;195:501-511.

5. Venieratos D, Panagouli E, Lolis E, Tsaraklis A, Skandalakis P. A Morphometric study of the celiac trunk and review of the literature. Clin Anat 2013;26(6):741-750.

6. Sürücü HS, Oto A, Gokoglu A, Celik HH, Ozdemir B, Besim A. Anatomy of the celiac trunk examined by CT imaging of 104 individuals. Morphologie 2003;87(277):33-35.

7. Lipshutz B. A composivy study of the celiac axis artery. Ann Surg 1917;65:159-169.

8. Michels NA. Blood supply and anatomy of the upper abdominal organs, with a descriptive atlas. Lippincot, Philadelphia, 1955.

9. Higashi N, Shimada H, Simamura E, Hatta T, Branching patterns of the celiac artery as the hepato-gastro-splenic trunk. Kaibogaku zasshi 2009;84:7-10.

10. Mburu KS, Alexander OJ, Hassan S, Bernard N. Variations in the branching pattern of the celiac trunk in a Kenyan population. Int J Morphol 2010;28:199-204.

11. Marco-Clement I, Martinez-Barco A, Ahumada N, Simon C, Valderrama JM, Sanudo J, Arrazola J. Anatomical variations of the celiac trunk: cadaveric and radiological study. Surg Radiol Anat 2016;38(4):501-510.

12. Iezzi R, Cotroneo AR, Giancristofaro D, Santoro M, Storto ML. Multidetector-row CT angiographic imaging of the celiac trunk: Anatomy and normal variants. Surg Radiol Anat 2008;30:303-310.

13. Aslaner R, Pekcevik Y, Sahin H, Toka O. Variations in the origin of inferior phrenic arteries and their relationship to celiac axis variations on CT angiography. Korean J Radiol 2017;18(2):336-344.

14. Natsis K, Paraskevas G, Panagouli E, et al. A morphometric study of multiple renal arteries in Greek population and a systematic review. Rom J Morphol Embryol 2014;55(3 Suppl):1111-1122.

15. Singh V. Textbook of Anatomy Abdomen and Lower Limb. Elsevier Health Sciences, Faridabad, 2014.

16. Chaikof EL, Cambria RP. Atlas of Vascular Surgery and Endovascular Therapy: Anatomy and Technique. Elsevier Health Sciences, Philadelphia, 2014.
17. Varghese K, Adhyapak S. Therapeutic Embolization. Springer, Bangalore, 2016.

18. Panagouli E, Tsaraklis A, Venieratos D. A lower polar additional renal artery in an ectopic intraperitoneal kidney. Folia Morphol 2011;70(1):56-58.

19. Papaloucas C, Fiska A, Demetriou T. Additional renal arteries. Clin Anat 2007;20(4):475.

17. Venieratos D, Panagouli E, Mazarakis A, Troupis T. Ipsilateral variations in the renal and vertebral arteries. Am Surg 2012;78(2):94-96.

21. Drake R, Vogl AW, Mitchell AWM. Gray's Basic Anatomy. Elsevier Health Sciences, Philadelphia, 2016.

22. Urken ML, Cheney ML, Blackwell KE, Harris JR, Hadlock TA, Futran N. Atlas of Regional and Free Flaps for Head and Neck Reconstruction: Flap Harvest and Insetting. Lippincott Williams \& Wilkins, Philadelphia, 2012.

23. Platzer W, Ronan O'Rahilly R. Atlas of topographical anatomy. G. Thieme Verlag, Berlin, 1985.

24. Doyle JR. Surgical Anatomy of the Hand and Upper Extremity. Lippincott Williams \& Wilkins, Philadelphia, 2003.

25. Mauro MA, Murphy KPJ, Thomson KR, Venbrux AC, Morgan RA. Image-Guided Interventions: Expert Radiology Series. Elsevier Health Sciences, Philadelphia, 2013.

26. Aastha, Jain A, Kumar MS. An unusual variation of axillary artery: a case report. J Clin Diagn Res 2015;9(1):AD05-7.

27. Naveen K, Jyothsna P, Nayak SB, et al. Variant origin of an arterial trunk from axillary artery continuing as profunda brachii artery--a unique arterial variation in the axilla and its clinical implications. Ethiop J Health Sci 2014;24(1):93-6.

28. Hutchison SJ, Holmes KC. Principles of Vascular and Intravascular Ultrasound. Elsevier Health Sciences, Philadelphia, 2011.

29. Halim A. Human Anatomy, Abdomen And Lower Limb. I. K. International Pvt Ltd, New Delhi, 2008.

30. Heberer G, van Dongen RJAM. Vascular surgery. Springer Science \& Business Media, Berlin, 2012.

31. Tubbs RS, Shoja MM, Loukas M. Bergman's Comprehensive Encyclopaedia of Human Anatomic Variation. John Wiley \& Sons, Hoboken, 2016.

32. Rajani SJ, Ravat MK, Rajani JK, Bhedi AN. Cadaveric study of profunda femoris artery with some unique variations. J Clin Diagn Res 2015;9(5):AC01-3.

33. Abrahams PH, Craven JL, Lumley JSP. Illustrated Clinical Anatomy, Second Edition. CRC Press, London, 2011.

34. Moore KL, Dalley AF, Agur AMR. Clinically Oriented Anatomy. Lippincott Williams \& Wilkins, Philadelphia, 2013.

35. White RA, MD, Hollier LH. Vascular Surgery: Basic Science and Clinical Correlations. John Wiley \& Sons, Malden, 2008.

36. Vučurević G, Marinković S, Puškaš L, Kovačević I, Tanasković S, Radak D, Ilić A. Anatomy and radiology of the variations of aortic arch branches in 1,266 patients. Folia Morphol (Warsz) 2013;72(2):113-22.

37. Al-Mubarak N. Carotid Artery Stenting: Current Practice and Techniques. Lippincott Williams \& Wilkins, Philadelphia, 2004.

38. Huempfner-Hierl H, Hierl T, Halama D. Rare anatomical variation of the brachiocephalic trunk encountered in tracheostomy. Br J Oral Maxillofac Surg 2017;55(3):312-313.

39. Casserly IP, Sachar R, Yadav JS. Manual of Peripheral Vascular Intervention. Lippincott Williams \& Wilkins, Philadelphia, 2005. 
40. Lazaridis N, Piagkou M, Loukas M, et al. A systematic classification of the vertebral artery variable origin: clinical and surgical implications. Surg Radiol Anat 2018.

doi: 10.1007/s00276-018-1987-3.

41. Grabherr S, Grimm JM, Heinemann A. Atlas of Postmortem Angiography. Springer, New York, 2016.

42. Panagouli E, Tsaraklis A, Gazouli I, Anagnostopoulou S, Venieratos D. A rare variation of the axillary artery combined contralaterally with an unusual high origin of a superficial ulnar artery: description, review of the literature and embryological analysis. Ital J Anat Embryol 2009;114(4):145-56.

43. Troupis TG, Michalinos A, Vlastos D, et al. Combined variations of superior mesenteric artery branches. Am Surg 2014;80(4):E103-4.

44. Tsoucalas G. Anatomy: an essential course for future surgeons. J Universal Surg 2018;6(1):8. 